\title{
Response Capacity of the Supply Chain Management in Emergency based on a New Multiple Attribute Decision Making Approach
}

\author{
Zebo Li \\ Southwest Petroleum University, Chengdu, Sichuan, China, 610500 \\ Address \\ 20726198@qq.com
}

\begin{abstract}
The emergency often has the characteristics of explosiveness and population diffusion. It is easy to lead to the creation of the public crisis. Once the emergency occurs, it often produces the negative influence on the supply chain which is well-designed and running well. And even it leads to paralysis of the supply chain. To respond to the emergency, we need the effective emergency management of the supply chain to ensure the unblocked of the supply chain. In this paper, we establish the evaluation system for the response capacity of the supply chain in emergency according to analyzing the response capacity of the supply chain in emergency. Then we put forward a new TOPSIS method which is based on the relative coefficient. This method can express the preference of the experts better. At the same time, this method considers the advantages and disadvantages of the decision scheme. We use the method to evaluate the response capacity of the supply chain in emergency. The experimental results show that the method is feasible and effective.
\end{abstract}

Keywords: Emergency response capacity; Supply chain; Emergency management; TOPSIS

\section{Introduction}

In recent years, the large scale public emergencies occur frequently. In the process of disposing the emergency, each department at all levels must have the quick response capacity of the supply chain to cope with various of emergencies. Because the development of the supply chain becomes more and more simplified. It also becomes more and more fragile. When facing the emergency, supply chain could not play its role to deal with the public emergency events. Researching the response capacity of the supply chain in emergency not only can enhance the resistivity ability of the supply chain itself, but also respond better the emergencies. It can achieve the goal to evaluate the capacity objectively and accurately.

The emergency management is the process of warning, controlling and processing the emergencies. Chinese and foreign scholars have studied the field extensively. Perrow put forward Normal Accident Theory and this theory exists widespread influence in the field of emergency management. Evan and Manion improved the design background of Perot, blended the factors of social culture and made the theory more prefect [2]. Fink used the medical terminology to analogy the stages of the crisis management. He thought that the crisis existed four stages. They were Prodromal, Breakout or Acute, Chronic and Resolution. At the same time, he thought that the crisis management should not confine the design of a crisis management plan. Crisis management should identify and prevent the crisis event actively [3]. Steven et al. address a gap in the literature regarding the concept of multi-agency coordination from a human-environment interaction perspective. They presented a theoretical framework for facilitating multi-agency coordination in 
emergency management that was grounded in human factors and ergonomics using the methodology of core-task analysis[4]. HuabaiandShizhen used a system analysis approach to construct a two-layer fuzzy comprehensive evaluation model of emergency management capacity about enterprise value network engineering based on RSA-ANPDSS research methods, which could provide a decision-making theory foundation for emergency management and improve emergency management capabilities to the "sudden adversity" or "sudden disaster" in the value network engineering [5]. Sheu and Pan proposed a method for designing a seamless centralized emergency supply network by integrating three sub-networks to support emergency logistics operations in response to large-scale natural disasters [6].Kelle et al. coordinated the two stages, the preparedness and response decisions, in a large hierarchical emergency supply chain to decrease the loss for the worst-case scenario, the min-max regret criterion could be applied for the pre-positioning decision [7]. Jia and Zhu analyzed the emergency logistics infrastructure network support, the network coordination mechanism, the emergency planning and emergency transportation. They used a two-objective optimization model to distribute the urgent relief to the identified affected area sets [8]. Taskina, Emmett and Lodree solved the stochastic inventory control problem for emergency supplies based on hurricane count predictions. The authors presented a control policy for emergency supplies to meet stochastic demands [9]. Ren and Salman.et al researched the emergency resource dispatching problem under uncertainty [1011]. In addition, Ha et al. studied the supply chain emergency capacity [12-13].

In 1981, Hwang put forward the method which was based on the ideal point principle. Firstly, the method determined an ideal point. The best scheme is the nearest to the ideal point. It can reduce the change which was caused by the preference of the evaluators. And it could not cause the uncertainty of the evaluation results. This method is one of the most used methods to support MCDM (Multiple criteria Decision Making)[14]. Tan proposed a generalized interval-valued intuitionistic fuzzy geometric aggregation operator which was used to aggregate decision makers' opinions in a group decision making process based on operational laws[15]. Krohling and Campanharo proposed a fuzzy TOPSIS for group decision making, which is applied to evaluate the ratings of response alternatives to a simulated oil spill [16]. Singh,Benyoucef, Chen, and Tsao did the related study [17-18].

To evaluate a set of alternatives, the decision maker should give preferences on each attribute for each alternative. However, it is difficult to express the decision maker's preferences accurately. Since fuzzy set was proposed by Zadeh[19], it has been successfully used for handling fuzzy decision making problems[20-22]. Atanassov[23] introduced the concept of intuitionistic fuzzy set(IFS), which as a generalization of the concept of fuzzy set considers the membership degree,the non-membership degree and the uncertain degree. Meanwhile, Atanassov[24] defined some operational laws of IFSs. The intuitionistic fuzzy set has received more and more attention since its appearance [2528]. Xudeveloped some intuitionistic fuzzy aggregation operators, including the intuitionistic fuzzy weighted averaging operator, intuitionistic fuzzy ordered weighted averaging operator, and intuitionistic fuzzy hybrid aggregation operator, which can be used to aggregate intuitionistic fuzzy information[29-30]. However, there are too many operators to select. So, we introduce TOPSIS(technique for order preference by similarity to an ideal) which is proposed by Hwang and Yoon[31], whose basic principle is to choose the alternative with the shortest distance from the positive ideal solution(PIS) and the farthest distance from the negative ideal solution(NIS).

When the emergency occurs, in order to transport the emergency materials and services to the affected areas quickly, the quick response of emergency materials and the emergency management of the supply chain are very important. Constructing the emergency management capacity of the supply chain not only improves the quality of the supply chain itself, but also reduces the loss which is brought by emergencies. And it also safeguards the people's life and property. The structure of this paper is as follows. The first section is the introduction. In this section, we introduce the relative problem 
background. In Section 2, it introduces the related concept and establishes the evaluation system for the response capacity of the supply chain in emergency. In Section 3, we propose a method to evaluate system for the response capacity of the supply chain in emergency. In Section 4, a case study is demonstrated to verify the proposed method. Finally, Section 5 concludes this paper.

\section{The Research on the Capability of the Supply Chain for the Emergency}

\subsection{The Definition and the Basic Characteristics of the Emergency}

The origin of the emergency can be traced back to the 90's of thelast century. For the connotation of the emergency, scholars have a different understanding. The focus of the dispute lies in the influence that the emergency causes. Emergency is the unexpected event which happens suddenly, ultra conventionally. And it is needed to solve immediately. Therefore, the emergency can also be called the crisis event. Because the emergency needs to cooperate with many parts, the emergency belongs to the public management category. According to the "public incident overall emergency preplan" that the nation releases and "The emergency response law" that China implements, we believed that the emergency happens suddenly, may cause great harm and be formed by the negative influence for China. Therefore, it must adopt the unconventional measures to deal with the incidents and disasters.

In real life, the emergency has different patterns and always changes. However, throughout all kinds of emergency, it has some features. The features are the sudden, complicated causes, and serious harm. In addition, the emergencies spread rapidly and have the greater negative influence for China. And all features interlace. There are many scholars studying the features of the emergency. C.H. Zhu thought that the unexpected event is equivalent to the crisis event [32]. Therefore, he summarized the features of the emergency as the paroxysmal, complexity, destructive, persistent and opportunity etc. X.Q.Zhu summarized the features of the emergency as the sudden, disruptive, critical, urgency and complexity etc [33]. There are many scholars summarizing the features of the emergency. However, these summaries are not comprehensive. The purpose of this paper is to study the respond ability of the emergency. Compared with the research purpose, we summarized the features of the emergency.

The first feature is the unpredictability. All of the emergencies have the unpredictability. The unpredictability shows specifically in two aspects. The two aspects are the time when the emergency happens and the place where the emergency happens. In addition, the process and the development of the emergency cannot be unpredictable.

The second feature is the destructiveness. In some sense, the sign of the emergency is the casualties and the property loss. No matter what the nature and scale of the emergency, it will cause the different degree damages on the economic and the political loss for our country and people.

The third feature is the complexity. Firstly, the reasons of the emergency are complex. Secondly, people cannot perceive the evolutional mechanism and the evolution path of the emergency. Lastly, there is a comprehensive and clear understanding for the emergency. Therefore, when we deal with the emergency, we are lack of the effective coping knowledge. And we lead to the complexity for dealing with the problem.

The fourth feature is the emergency. The emergency happens suddenly. People could not foresee. Because of the destructive and the crisis, we must dispose urgently and immediately.

The fifth feature is the persistent. Firstly, from the development of the human society, the emergency has been accompanied by human beings and never stops. In addition, it will be associated with human forever. Secondly, for one emergency, the emergency 
comes suddenly. However, it does not disappear suddenly. Once the emergency breaks out, it will continue for some time.

\subsection{The Establishment of the Evaluation System for the Response Capacity of the Supply Chain in Emergency}

The emergency event management activity aims to reduce the loss to the minimum in the process operation of the whole emergency according to establishing the necessary coping mechanism and adopting a series of measures to ensure the public life and property security. The evaluation system for the response capacity of the supply chain in emergency is to evaluate comprehensively the emergency supply level and capacity of the supply chain for the expected event. If we find the deficiency and shortcoming that supply chain exists, we need to strengthen the construction of the supply chain emergency capacity and provide the advantageous basis for improving supply chain emergency capacity. J.Xu and D.B. Zhang established the emergency evaluation model for agricultural products supply chain [34]. Mohan etc. evaluated the reliability the automated collision notification systems [35]. Y.W.Deng and S.X.Zheng studied the city emergency capability assessment system and established the evaluation system for city response capacity [36]. Then, they used Kappa statistical method to analyze the city response capacity [37].In order to evaluate and study the emergency capacity for the emergency supply chain coordination mechanism, we need to establish a complete set of evaluation system. The evaluation system must be objective, scientific and reasonable. And the evaluation system needs to reflect the emergency capacity under the emergency supply chain coordination mechanism.

According to the domestic with the relevant foreign research, we construct the supply chain emergency capacity evaluation system which can reflect the unexpected event comprehensively.

Table 1. The Meaning of the Indicators

\begin{tabular}{|c|c|c|}
\hline \multirow{22}{*}{$\begin{array}{l}\text { The evaluation } \\
\text { system for the } \\
\text { response capacity of } \\
\text { the supply chain in } \\
\text { emergency }\end{array}$} & \multirow{11}{*}{$\begin{array}{c}\text { Public } \\
\text { Management } \\
\text { Capacity }\end{array}$} & Emergency Material Raise Capacity \\
\hline & & Emergency Material Reserve Capacity \\
\hline & & Emergency Material Transport Capacity \\
\hline & & Emergency Material Distribution Capacity \\
\hline & & The Fast Response Capacity \\
\hline & & The Government Coordination Capacity \\
\hline & & The Scientific Decision Capacity \\
\hline & & The Social Mobilization Capacity \\
\hline & & The Dispatching Capacity \\
\hline & & The Capacity of Mobilizing the Whole People \\
\hline & & Human Resource Preparation \\
\hline & \multirow{10}{*}{$\begin{array}{l}\text { The Basic } \\
\text { Capacity }\end{array}$} & Emergency Logistics Center Planning \\
\hline & & The Cost Control Capacity \\
\hline & & The Monitoring and Warning Capacity \\
\hline & & The Unblocked Degree of the Transport Channel \\
\hline & & The Logistics Equipment \\
\hline & & The Emergency Material Preparation \\
\hline & & The Emergency Material Preparation \\
\hline & & The Transportation Network Layout \\
\hline & & The Emergency Report \\
\hline & & The Emergency Notification \\
\hline & $\begin{array}{l}\text { Information } \\
\text { Management }\end{array}$ & $\begin{array}{c}\text { The Disaster Monitoring and Warning } \\
\text { Technology }\end{array}$ \\
\hline
\end{tabular}




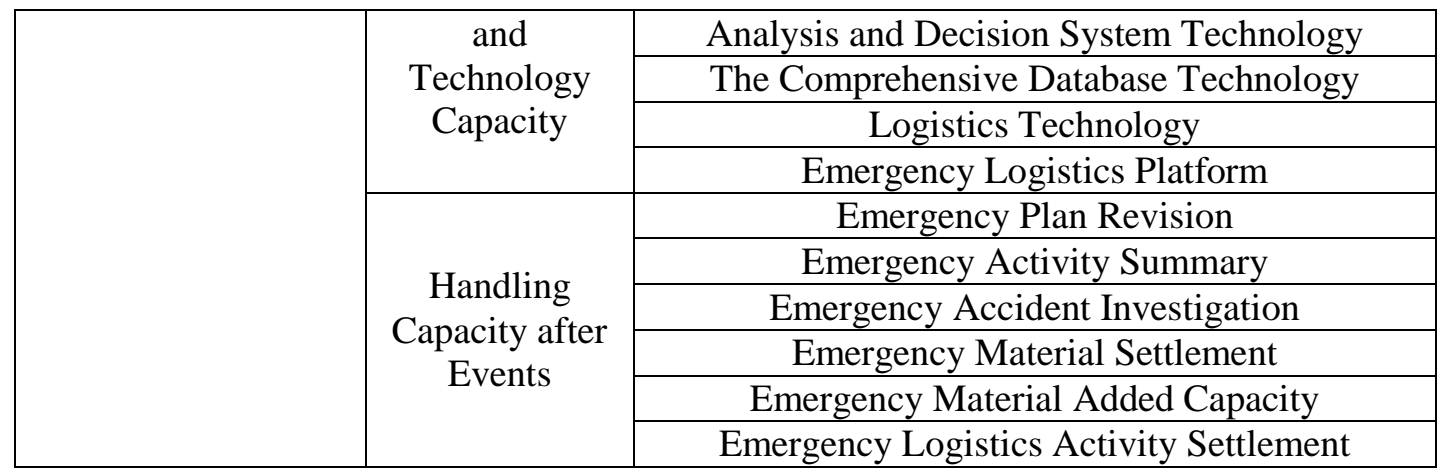

\section{Proposed Method}

In this section, according to intuitionistic fuzzy sets, we introduce correlation coefficient in TOPSIS approach instead of a distance measure to solve multiple attribute decision making problems.

\subsection{The Intuitionistic Fuzzy Sets}

Intuitionistic fuzzy set, as an extension of the concept of fuzzy set, is characterized by a membership degree, a non-membership degree and a uncertainty degree to describe fuzzy and hesitancy more proper. Thus, firstly, we review some basic concepts of intuitionistic fuzzy sets.

Definition 1[29] Le $\mathrm{t} X$ be an ordinary finite non-empty set. An intuitionistic fuzzy set in $X$ is an expression $A$ given by

$$
A=\left\{\left\langle x, u_{A}(x), v_{A}(x)\right\rangle \mid x \in X\right\}
$$

where $u_{A}: X \rightarrow[0,1]$ denotes the degree of membership and $v_{A}: X \rightarrow[0,1]$ denotes the degree of non-membership with the condition: $0 \leq u_{A}+v_{A} \leq 1$, for all $x$ in $X$.

For each intuitionistic fuzzy set $A$ in $X$, if the amount

$$
\pi_{A}(x)=1-u_{A}(x)-v_{A}(x), \forall x \in X .
$$

Then $\pi_{A}(x)$ is called the degree of indeterminacy of $x$ to $A$.Especially, if

$$
\pi_{A}(x)=1-u_{A}(x)-v_{A}(x)=0, \forall x \in X .
$$

Thus, the intuitionistic fuzzy set $A$ is reduced to a fuzzy set. For computational convenience, in this paper, we call $\left(u_{A}(x), v_{A}(x)\right)$ as an intuitionistic fuzzy value.

Definition 2[30] Let $a=\left(u_{a}, v_{a}\right)$ and $b=\left(u_{b}, v_{b}\right)$ be two intuitionistic fuzzy numbers, then

(1) $a \oplus b=\left(u_{a}+u_{b}-u_{a} u_{b}, v_{a} v_{b}\right)$;

(2) $a \otimes b=\left(u_{a} u_{b}, v_{a}+v_{b}-v_{a} v_{b}\right)$;

(3) $\lambda a=\left(1-\left(1-u_{a}\right)^{\lambda},\left(v_{a}\right)^{\lambda}\right), \lambda>0$;

(4) $a^{\lambda}=\left(\left(u_{a}\right)^{\lambda}, 1-\left(1-v_{a}\right)^{\lambda}\right), \lambda>0$.

Definition 3[30] Given two intuitionistic fuzzy values $A$ and $B$, the following operations are valid:

(1) $a \oplus b=b \oplus a$;

(2) $\lambda_{1}(a \oplus b)=\lambda_{1} a \oplus \lambda_{1} b$;

(3) $\lambda_{1} a \oplus \lambda_{2} a=\left(\lambda_{1}+\lambda_{2}\right) a$. 
Considering the operational characteristic of intuitionistic fuzzy set, we introduce the correlation coefficient between the intuitionistic fuzzy sets: the correlation coefficient and the weighted correlation coefficient.

Definition 4[30]. Let $M=\left\{\left\langle x, u_{M}(x), v_{M}(x)\right\rangle \mid x \in X\right\}$ and $N=\left\{\left\langle x, u_{N}(x), v_{N}(x)\right\rangle \mid x \in X\right\}$ be two intuitionistic fuzzy sets. The correlation of them can be defined as follows:

$$
C(M, N)=\sum_{i=1}^{n}\left(u_{M}\left(x_{i}\right) u_{N}\left(x_{i}\right)+v_{M}\left(x_{i}\right) v_{N}\left(x_{i}\right)\right)
$$

Considering the degree of indeterminacy of a hesitant fuzzy number, we define a new correlation coefficient between two hesitant fuzzy sets.

\subsection{Decision Making Procedure based on TOPSIS Approach}

In traditional TOPSIS approach, the deviation between the alternative and the positive ideal solution or the negative ideal solution is measured by distance. Its basic principle is to choose the alternative which has the smallest distance to the positive ideal solution and the biggest distance to the negative ideal solution. In this section, we extend the TOPSIS with correlation coefficient instead of a distance measure in the procedure of decision making problem. The proposed TOPSIS's basic principle is to choose the alternative which has the biggest correlation coefficient to the positive ideal solution and the smallest correlation coefficient to the negative ideal solution. The correlation is introduced to compare the alternative with the positive ideal solution or the negative ideal solution.

Under intuitionistic fuzzy environment, the intuitionistic fuzzy PIS, denoted by $A^{+}$, and the intuitionistic fuzzy NIS, denoted by $A^{-}$can be defined as follows:

$$
\begin{aligned}
& A^{+}=\left\{x_{j}, \max _{i}\left\langle u\left(x_{j}\right)\right\rangle, \min _{i}\left\langle v\left(x_{j}\right)\right\rangle \mid j=1,2, \mathrm{~L}, n\right\} \\
& A^{-}=\left\{x_{j}, \min _{i}\left\langle u\left(x_{j}\right)\right\rangle, \max _{i}\left\langle v\left(x_{j}\right)\right\rangle \mid j=1,2, \mathrm{~L}, n\right\}
\end{aligned}
$$

In order to simplify, we use the Eq. (5) and Eq. (6) instead of the Eq. (3) and Eq. (4).

$$
\begin{aligned}
& A^{+}=\left\{x_{j}, 1,0,0 \mid j=1,2, \mathrm{~L}, n\right\} \\
& A^{-}=\left\{x_{j}, 0,1,0 \mid j=1,2, \mathrm{~L}, n\right\}
\end{aligned}
$$

The relative closeness coefficient of an alternative $A_{i}$ with respect to the intuitionistic fuzzy PIS $A^{+}$is expressed as follows:

$$
C C_{i}=\frac{\rho_{i}^{+}}{\rho_{i}^{+}+\rho_{i}^{-}}
$$

where $0 \leq C C_{i} \leq 1, i=1,2, \ldots, m$. Obviously, when an alternative is closer to the intuitionistic fuzzy PIS and farther from the intuitionistic fuzzy NIS, $C C_{i}$ will be closer to 1. Hence, according to the closeness coefficient $C C_{i}$, the ranking-order of all alternatives can be determined and the best alternative can be selected. According to mentioned models, we can present a novel approach to solve MADM problem, where attribute values take the form of intuitionistic fuzzy sets. The approach involves the following step:

Step1. For a MADM problem, we construct the decision matrix $D=\left[\varepsilon_{i j}\right]_{m \times n}$, where all the arguments $\mathscr{E}_{i j}(i=1,2, \ldots m ; j=1,2, \ldots n)$ are IFS, given by the decision maker. As for every alternative $a_{i}(i=1,2, \ldots, m)$, the decision maker is invited to express evaluation or preference according to each attribute $c_{j}(j=1,2, \ldots, n)$ by a intuitionistic fuzzy value $\mathscr{B}_{i j}=\left(u_{i j}, v_{i j}, \pi_{i j}\right)(i=1,2 \mathrm{~L}, m ; j=1,2, \mathrm{~L}, n)$, where $u_{i j}$ indicates the hesitant degree that the decision maker considers what the alternative $\alpha_{i}$ should satisfy the criteria $c_{j}$, $v_{i j}$ indicates the hesitant degree that expert e considers what the alternative $\alpha_{i}$ should not 
satisfy the criteria $c_{j}$.Then we can obtain a decision making matrix as follow:

$$
D=\left(\begin{array}{cccc}
\tilde{a}_{11} & \tilde{a}_{12} & \cdots & \tilde{a}_{1 n} \\
\tilde{a}_{21} & \tilde{a}_{22} & \cdots & \tilde{a}_{2 n} \\
\vdots & \vdots & \ddots & \vdots \\
\tilde{a}_{m 1} & \cdots & \cdots & \tilde{a}_{m n}
\end{array}\right)
$$

Step 2: Utilize Eq.(5) and Eq. (6) to determine the corresponding intuitionistic fuzzy $\mathrm{PISA}^{+}$and the intuitionistic fuzzy NISA:

$$
\begin{aligned}
& P I S A^{+}=(\{1\}\{0\}\{0\}) \\
& N I S A^{-}=(\{0\}\{1\}\{0\})
\end{aligned}
$$

Step 3: Utilize the intuitionistic fuzzy correlation coefficient to calculate the correlation between the alternative $\alpha_{i}$ and the PIS $A^{+}$and the correlation between the alternative $\alpha_{i}$ and the NISA ${ }^{-}$.

$$
\begin{gathered}
\rho_{I F W}\left(A, A^{*}\right)=\frac{C\left(A, A^{*}\right)}{\sqrt{C\left(A, A^{*}\right)} \cdot \sqrt{C\left(A, A^{*}\right)}} \\
\rho^{+}=\frac{\sum_{j=1}^{n} w_{j}\left(u_{A}\left(x_{j}\right)\right)}{\left\{\sum_{j=1}^{n} w_{j}\left[u_{A}^{2}\left(x_{j}\right)+v_{A}^{2}\left(x_{j}\right)+\pi_{A}^{2}\left(x_{j}\right)\right]\right\}^{\frac{1}{2}}} \\
\rho^{-}=\frac{\sum_{j=1}^{n} w_{j}\left(v_{A}\left(x_{j}\right)\right)}{\left\{\sum_{j=1}^{n} w_{i}\left[u_{A}^{2}\left(x_{j}\right)+v_{A}^{2}\left(x_{j}\right)+\pi_{A}^{2}\left(x_{j}\right)\right]\right\}^{\frac{1}{2}}}
\end{gathered}
$$

Step 4: Calculate the closeness coefficient of each alternative:

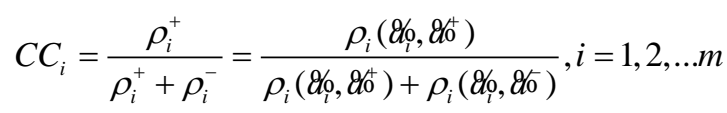

Step 5: Rank all the alternative $a_{i}$ according to the closeness coefficient $C C_{i}$, where the greater the value $C C_{i}$, the better the alternative $a_{i}$.

Step 6: End.

\section{Numerical Example}

In this section, an evaluation problem of is analyzed by the proposed method to demonstrate its applicability and validity.

In real life, the most evaluation framework need exact information of decision maker's preference. It is difficult to obtain accurate preference of decision maker. Then, we introduce fuzzy expression to solve this problem as discussed in Section 1. A relevant expert from a famous university acts as the decision maker. He chooses five regions denoted as $a_{1}, a_{2}, a_{3}, a_{4}, a 5$. Meanwhile, he identifies four basic attributes based on the former studies denoted as $c_{1}, c_{2}, c_{3}, c_{4}$ in Table 1and specifies $w=(0.35,0.25,0.3,0.1)$. In Table 1, we explain four attributes through some more specific indicators.

As mentioned above, the proposed method which extends the TOPSIS approach with correlation coefficient is introduced to evaluate the unexpected event supply chain emergency capacity of the five regions. The evaluation model is demonstrated in the Figure.1. 


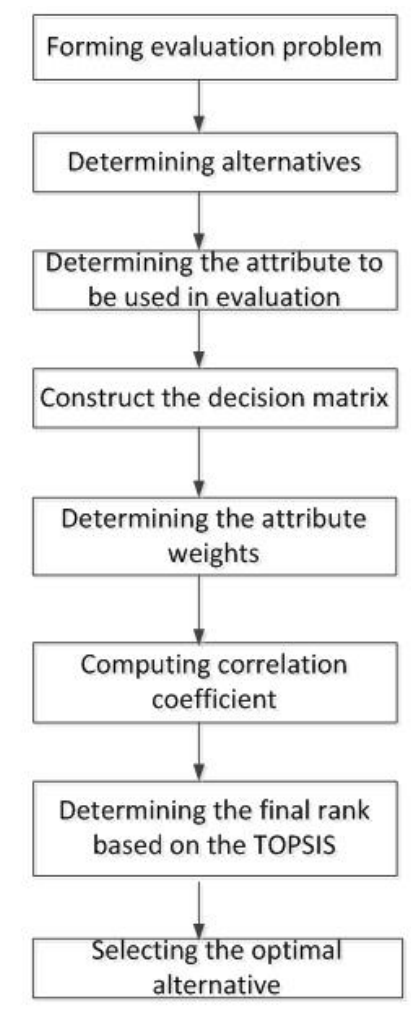

Figure 1. The Evaluation Model

Based on the evaluation model, with respect to attributes $c_{j}(j=1,2, \mathrm{~L}, n)$ the evaluation of the alternative $a_{i}(i=1,2, \mathrm{~L}, m)$ is made by an intuitionistic fuzzy numbers $\mathscr{E}_{i j}=\left(u_{i j}, v_{i j}, \pi_{i j}\right)(i=1,2 \mathrm{~L}, m ; j=1,2, \mathrm{~L}, n)$. Then we can obtain a decision making matrix as follow:

Table 2. The Transpose of Intuitionistic Fuzzy Decision Matrix

\begin{tabular}{|c|c|c|c|c|c|}
\hline Attributes & $a_{1}$ & $a_{2}$ & $a_{3}$ & $a_{4}$ & $a_{5}$ \\
\hline$c_{1}$ & $\begin{array}{l}\{0.5\}\{0.4\}\{0 \\
.1\}\end{array}$ & $\{0.4\}\{0.6\}$ & $\begin{array}{l}\{0.4\}\{0.4\}\{0 \\
.2\}\end{array}$ & $\begin{array}{l}\{0.2\}\{0.1\} \\
\{0.7\}\end{array}$ & $\begin{array}{l}\{0.6\}\{0.2\}\{0 . \\
2\}\end{array}$ \\
\hline$c_{2}$ & $\begin{array}{l}\{0.6\}\{0.3\}\{0 \\
.1\}\end{array}$ & $\begin{array}{l}\{0.7\}\{0.1\}\{ \\
0.2\}\end{array}$ & $\begin{array}{l}\{0.4\}\{0.5\}\{0 \\
.1\}\end{array}$ & $\{0.8\}\{0.2\}$ & $\begin{array}{l}\{0.6\}\{0.3\}\{0 . \\
1\}\end{array}$ \\
\hline$c_{3}$ & $\begin{array}{l}\{0.2\}\{0.6\}\{0 \\
.2\}\end{array}$ & $\begin{array}{l}\{0.5\}\{0.2\}\{ \\
0.3\}\end{array}$ & $\begin{array}{l}\{0.6\}\{0.2\}\{0 \\
.2\}\end{array}$ & $\begin{array}{l}\{0.4\}\{0.2 \\
\}\{0.4\}\end{array}$ & $\begin{array}{l}\{0.3\}\{0.5\}\{0 . \\
2\}\end{array}$ \\
\hline$c_{4}$ & $\{0.8\}\{0.2\}$ & $\begin{array}{l}\{0.6\}\{0.3\}\{ \\
0.1\}\end{array}$ & $\begin{array}{l}\{0.3\}\{0.3\}\{0 \\
.4\}\end{array}$ & $\begin{array}{l}\{0.5\}\{0.4\} \\
\{0.1\}\end{array}$ & $\begin{array}{l}\{0.4\}\{0.5\}\{0 . \\
1\}\end{array}$ \\
\hline
\end{tabular}

According to Eqs (5) and (6), the corresponding intuitionistic fuzzy $\mathrm{PISA}^{+}$and the intuitionistic fuzzy NISA ${ }^{-}$can be acquired. The correlation coefficient between the each alternative $\alpha_{i}$ and the $\mathrm{PISA}^{+}$and between the each alternative $\alpha_{i}$ and the $\mathrm{NISA}^{-}$can be calculated: 


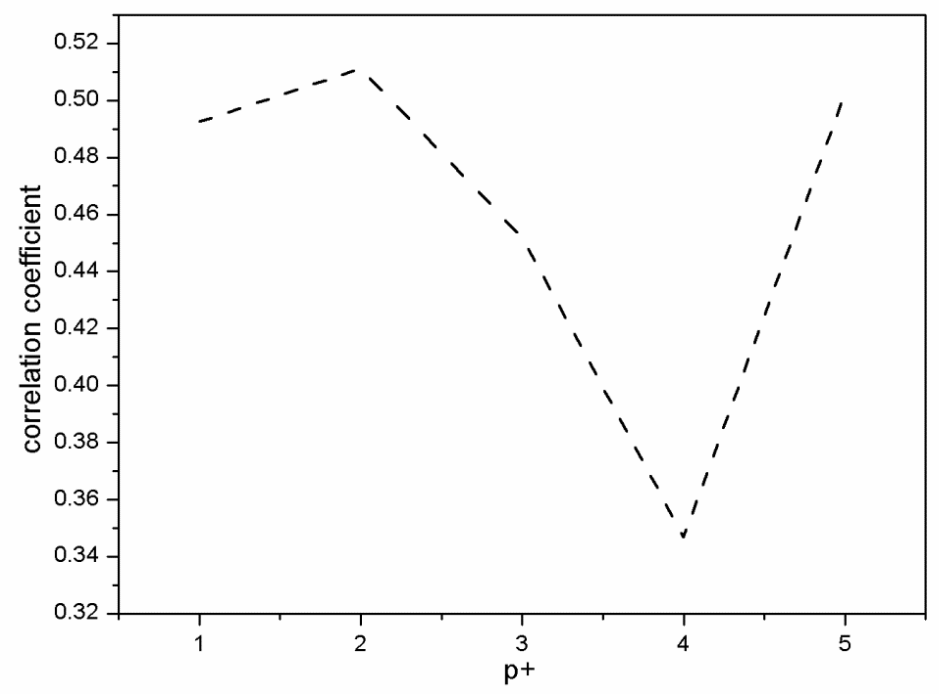

Figure 2. Correlation Coefficient of Each Alternative to Positive Ideal Solution

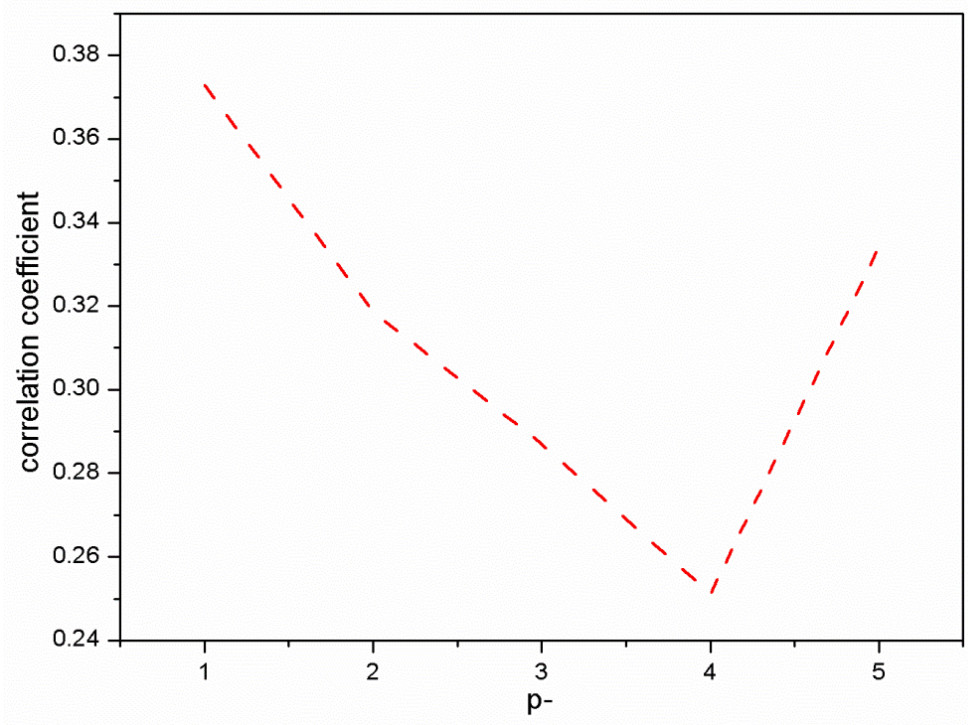

Figure 3. Correlation Coefficient of Each Alternative to Negative Ideal Solution

Based on the correlation coefficient, the closeness coefficient of each alternative can be obtained:

Table 3. The Closeness Coefficient of Each Alternative

\begin{tabular}{|l|l|}
\hline & $C C_{i}$ \\
\hline$a_{1}$ & 0.5692 \\
\hline$a_{2}$ & 0.6161 \\
\hline$a_{3}$ & 0.6115 \\
\hline$a_{4}$ & 0.58 \\
\hline$a_{5}$ & 0.6006 \\
\hline
\end{tabular}


According to the closeness coefficient $C C_{i}$, the rank-order of all the alternative $a_{i}$ can be demonstrated: $a_{2} \mathrm{f} \quad a_{3} \mathrm{f} \quad a_{5} \mathrm{f} \quad a_{4} \mathrm{f} \quad a_{1}$. Therefore, we can acquire that the $a_{2}$ is the best alternative.

\section{Conclusion}

The large scale public emergencies cause the heavy casualties and economic loss. Responding to the emergency must involve many departments. In order to solve the emergencies better, we must improve the emergency capacity of the supply chain to help the injured people, health and epidemic prevention, post disaster reconstruction and the production restoration. Otherwise, the disaster loss may increase. The key of improving the emergency capacity of the supply chain is to reduce the disaster loss and ensure the stable social development.

In this paper, we have the following innovation points: (1) the evaluation system for the response capacity of the supply chain in emergency is established;(2) the introduction of intuitionistic fuzzy set to express the decision maker's preference more exactly considering membership degree, non-membership degree and uncertainty degree; (3) the introduction of correlation coefficient instead of distance measure to be applied in TOPSIS method to aggregate the decision information of different attributes which impact supply chain emergency capacity;(4) the definition of the new correlation coefficient by considering the basic characteristic of intuitionistic fuzzy sets; (5) the creation of a novel assessment model to help different enterprise improve their supply chain emergency capacity. But, there are still some shortcomings in this paper. For example, evaluation system for the response capacity of the supply chain in emergency is to settle. The proposed method in this paper cannot solve more complex problems such as group decision making problems. In the future research, we can make dynamic evaluation for response capacity of the supply chain in emergency. So, the decision maker can assess this emergency supply chain according to the reality. More importantly, group decision making methods can be introduced and improved.

\section{Acknowledgment}

Science and Technology Fund Project of Southwest Petroleum University: A Study on Innovative Campus Security Management Model of Specialized Universities of Sichuan Province - A Case Study of Southwest Petroleum University(No.2012XJR023)

\section{Reference}

[1] C. Perrow, "Normal accident at three Mile Island", Society, vol. 18, no. 5, (1981), pp. 17-26.

[3] S. Yinghua, "The introduction of emergency management", China Economic Publishing House, (2009).

[3] S.Fink, "Crisis management: Planning for the inevitable", New York: American Management Asociation, (1986).

[4] S. Curnina, C. Owena, D. Patonb and B. Brooks, "A theoretical framework for negotiating the path of emergency management multi-agency coordination", Applied Ergonomics, vol. 47, (2015), pp. 300-307.

[5] B. Huabai and B. Shizhen. "Two-Layer Fuzzy Comprehensive RSA-ANP-DSS Evaluation Model of Emergency Management Capacity about Enterprise Value Network", Systems Engineering Procedia, (2012).

[6] J. B. Sheu and C. Pan, "A method for designing centralized emergency supply network to respond to large-scale natural disasters”, Transportation Research Part B: Methodological, vol. 67, (2014), pp. 284305.

[7] P. Kelle, H. Schneider and H. Z. Yi, "Decision alternatives between expected cost minimization and worst case scenario in emergency supply - Second revision", International Journal of Production Economics, vol. 157, (2014), pp. 250-260.

[8] G. J. Jia and C. H. Zhu, "A Study on Emergency Supply Chain and Risk Based on Urgent Relief Service in Disasters", Systems Engineering Procedia, (2012).

[9] S. Taskina, J. Emmett and J. Lodree, "Inventory decisions for emergency supplies based on hurricane count predictions", International Journal of Production Economics, vol. 126, no. 1, (2010), pp. 66-75. 
[10] X. Ren, J. M. Zhu and J. Huang, "Multi-period Dynamic Model for Emergency Resource Dispatching Problem in Uncertain Traffic Network", Systems Engineering Procedia, (2012).

[11] F. S. Salman and E. Yücel, "Emergency facility location under random network damage: Insights from the Istanbul case, Computers \& Operations Research, Press, Accepted Manuscript, (2014).

[12] X. H. Ha, W. F. Hu, J. H. Wu and C. X. Wang, "Improving Emergency Goods Transportation Performance in Metropolitan Areas under Multi-echelon Queuing Conditions", Procedia Social and Behavioral Sciences, (2013).

[13] A. B. Tal, B. D. Chung, S. R. Mandala and T. Yao, "Robust optimization for emergency logistics planning: Risk mitigation in humanitarian relief supply chains", Transportation Research Part B: Methodological, vol. 45, no. 7, (2011), pp. 1177-1189.

[14] S. Chen and C. L. Hwang, "Multiple Attribute Decision Making: Method and Applications", New York: Spring- Verlag, (1981)

[15] C. Q. Tan, "A multi-criteria interval-valued intuitionistic fuzzy group decision making with Choquet integral-based TOPSIS", Expert Systems with Applications, vol. 38, no. 4, (2011), pp. 3023-3033.

[16] R. A. Krohling and V. C. Campanharo, "Fuzzy TOPSIS for group decision making: A case study for accidents with oil spill in the sea", Expert Systems with Applications, vol. 38, no. 4, (2011), pp. 41704197.

[17] R. K. Singh and L. Benyoucef, "A fuzzy TOPSIS based approach for e-sourcing”, Engineering Applications of Artificial Intelligence, vol. 24, no. 3, (2011), pp. 437-448.

[18] T. Y. Chen and C. Y. Tsao, "The interval-valued fuzzy TOPSIS method and experimental analysis", Fuzzy Sets and Systems, vol. 159, no. 11, (2008), pp. 1410-1428.

[19] L. A. Zadeh, "Fuzzy sets", Information and Control, vol. 8, (1965), pp. 338-356.

[20] H. Bustine and P. Burillo, "Vague sets are intuitionistic fuzzy sets", Fuzzy Sets and Systems Science, vol. 79, (1996), pp. 403-405.

[21] H. J. Zimmermann, "Fuzzy Set Theory and Its Applications", Kluwer Academic Publishers, Dordrecht, (1985).

[22] D. Guha and D. Chakraborty, "A new approach to fuzzy distance measure and similarity measure between two generalized fuzzy numbers", Applied Soft Computing, vol. 10, (2010), pp. 90-99.

[23] K. Atanassov and G. Gargov, "Intuitionistic fuzzy logic", C. R. Acard. Bulgare, Sc., vol. 43, no. 3, (1990), pp. 9-12.

[24] K. Atanassov, G. Pasi and R. Yager, "Intuitionistic fuzzy interpretations of multi-criteria multi-person and multi-measurement tool decision", International Journal of systems Science, vol. 36, (2005), pp. 859-868.

[25] F. E. Boran, S. Genc, M. Kurt and D. Akay, "A multi-criteria intuitionistic fuzzy group decision making for supplier selection with TOPSIS method", Expert Systems with Application, vol. 36, (2003), pp. 11363-11368

[26] C. Q. Tan and X. H. Chen, "Intuitionistic fuzzy Choquet integral operator for multi-criteria decision making", Expert Systems with Application, vol. 37, (2010), pp. 149-157.

[27] S. K. De, R. Biswas and A. R. Roy, "An application of intuitioistic fuzzy sets in medical diagnosis", Fuzzy Sets and Systems, vol. 17, (2011), pp. 209-213.

[28] Z. S. Xu and J. Chen, "An overview of distance and similarity measures of intuitionistic fuzzy sets", International Journal of Uncertainty, Fuzziness and Knowledge-based Systems, vol. 16, (2008), pp. 529555.

[29] Z. S. Xu, "Intuitionistic fuzzy aggregation operators", IEEE Transaction Fuzzy Systems, vol. 15, (2007), pp. 1179-1187.

[30] Z. S. Xu and R. R. Yager, "Some geometric aggregation operators based on intuitionistic fuzzy sets", International Journal of General Systems, vol. 35, (2006), pp. 417-433.

[31] C. L. Hwang and K. Yoon, "Multiple Decision Making: Methods and Applications", Springer, (1981).

[32] C. H. Zhu, "Study on supply chain disruption management based on disruptions", Xiamen University, Management Science and Engineering, (2008).

[33] X. Q. Zhu, "Research on the resilient supply chains for emergencies", Wuhan University of Technology, Business Administration, (2011).

[34] J. Xu and D. B. Zhang, "The evaluation model of agricultural products supply chain in emergency", Statistics and Decision, vol. 12, (2012), pp. 41-43.

[35] R. Mohan, C. B. Akellaa, R. Beumerc, M. Eric, R. Battab, A. Blatta, A. Peter and G. Wilsona, "Evaluating the Reliability of Automated Collision Notification Systems", Accifent Analysis \& Prevention, (2003), vol. 35, no. 3, pp. 349-360.

[36] Y. W. Deng and S. X. Zheng, "Study on city emergency capability assessment system", Journal of Safety Science and Technology, vol. 6, (2005), pp. 21-25.

[37] Y. W. Deng and S. X. Zheng, "The Kappa Analysis of city emergency capability assessment system", Journal of Safety Science and Technology, vol. 2, (2006), pp. 32-35. 
International Journal of $u-$ and e- Service, Science and Technology Vol.9, No. 1 (2016) 